\title{
Capsule endoscopy practice during the COVID-19 pandemic: Recommendations from the Capsule Endoscopy Group of the Chinese Society of Digestive Endoscopy
}

\section{(ㄷ)(1) $(2)$}

Authors

Zhuan Liao' ${ }^{1}$, Shuixiang He², Weihong Sha ${ }^{3}$, Zhijie Feng ${ }^{4}$, Xiaomei Sun ${ }^{5}$, Jun Wan ${ }^{6}$, Jun Pan ${ }^{1}$, Shasha Wang ${ }^{7}$, Enqiang Linghu ${ }^{7}$, Zhaoshen $\mathrm{Li}^{1}$, on behalf of the Capsule Endoscopy Group of the Chinese Society of Digestive Endoscopy

Institutions

1 Department of Gastroenterology, Changhai Hospital, Shanghai, China

2 Department of Gastroenterology, The First Affiliated Hospital of Xi'an Jiaotong University, Xi'an, Shaanxi, China

3 Department of Gastroenterology, Guangdong Provincial People's Hospital, Guangzhou, Guangdong, China

4 Department of Gastroenterology, The Second Hospital of Hebei Medical University, Shijiazhuang, Hebei, China.

5 Digestive Disease Hospital of Heilongjiang Provincial Hospital, Harbin, Heilongjiang, China

6 Department of Gastroenterology, The Second Medical Center of Chinese PLA General Hospital, Beijing, China

7 Department of Gastroenterology, The First Medical Center of Chinese PLA General Hospital, Beijing, China

submitted 25.6.2020

accepted after revision 11.11 .2020

Bibliography

Endoscopy International Open 2021; 09: E280-E283

DOI 10.1055/a-1333-6635

ISSN 2364-3722 (c) 2021. The Author(s).

This is an open access article published by Thieme under the terms of the Creative Commons Attribution-NonDerivative-NonCommercial License, permitting copying and reproduction so long as the original work is given appropriate credit. Contents may not be used for commecial purposes, or adapted, remixed, transformed or built upon. (https://creativecommons.org/licenses/by-nc-nd/4.0/)

Georg Thieme Verlag KG, Rüdigerstraße 14,

70469 Stuttgart, Germany

Corresponding author

Zhuan Liao, Department of Gastroenterology, Changhai

Hospital, 168 Changhai Road, Shanghai 200433, China

Fax: +86-21-65492727

liaozhuan@smmu.edu.cn

\section{ABSTRACT}

The Capsule Endoscopy Group of the Chinese Society of Digestive Endoscopy has issued recommendations for capsule endoscopy (CE) practice during the COVID-19 pandemic to standardize workflow, preventive strategies, and management of a CE unit and in so doing, ensure the safety of both medical staff and patients.

\section{Advantages of capsule endoscopy}

In the context of the COVID-19 pandemic [1], capsule endoscopy (CE) has unique advantages over other gastrointestinal endoscopy modalities [2-5], including single use with low risk of cross-infection, excellent tolerance with low risk of aerosol generation, minimal medical staff requirement (one staff member only), and separation of examination and reading/reporting $[6,7]$. Recent introduction of the noncontact magnetically controlled capsule endoscopy (MCE) system ( $\triangleright$ Fig.1) [8], which separates patients and medical staff in different rooms or glass-partition-divided rooms, allows for infection-free upper gastrointestinal examination (especially the stomach) under remote control, ensuring the safety of medical staff while providing high-quality endoscopy service for patients.

\section{Recommended indications for capsule endoscopy}

Recommended indications for CE examination during the COVID-19 pandemic are classified as urgent, semi-urgent and elective ( $\triangleright$ Table 1 ). We recommend suspected acute small bowel (SB) bleeding (eg, nonhematemesis gastrointestinal bleeding after negative esophagogastroduodenoscopy (EGD) and colonoscopy) as the indication for urgent SBCE [6], in accordance with the European Society for Gastrointestinal Endoscopy position statement that lists "capsule/enteroscopy for urgent/ emergent bleeding" among the "perform always" gastrointestinal endoscopy procedures [4]. Because accumulating evidence suggests that $C E$ is effective for detecting bleeding source and triaging patients who do not require hospital admis- 


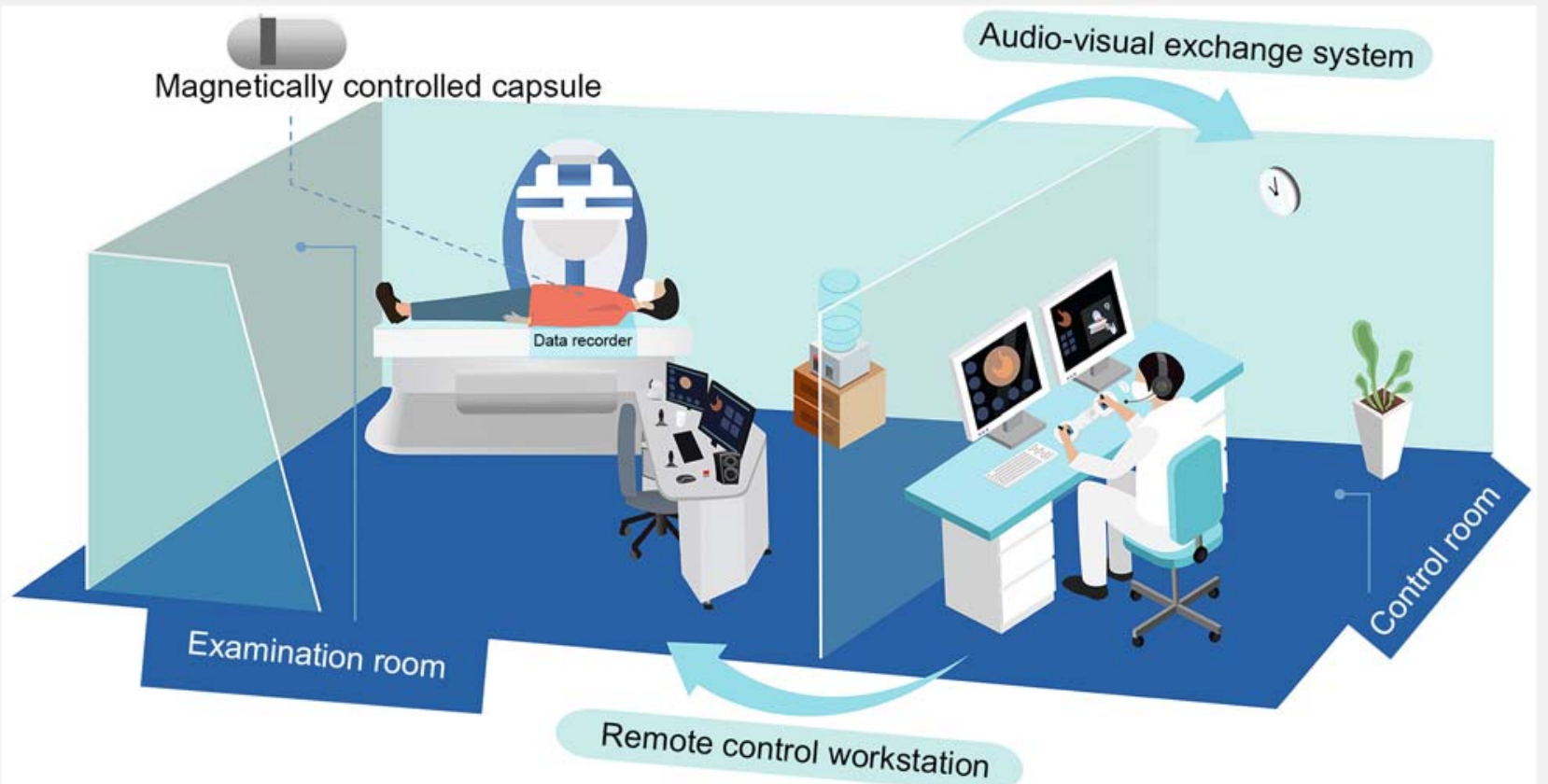

- Fig. 1 Noncontact magnetically controlled capsule endoscopy system. The system consists of a robotic magnetic arm, a workstation (currently bypassed), a capsule endoscope, a remote-control workstation, and an audiovisual exchange system.

sion for acute upper gastrointestinal bleeding [9-11], we recommend stable acute upper gastrointestinal bleeding as the indication for urgent CE (esophageal/ upper gastrointestinal/ SB capsule), MCE or noncontact MCE [8] during the COVID-19 pandemic (EGD is also recommended and performance is at the doctor's discretion). Because MCE has exhibited potential for upper gastrointestinal cancer diagnosis [12,13], we recommend suspected upper gastrointestinal cancer as the indication for semi-urgent MCE or noncontact MCE [8]. As for lower gastrointestinal cancer diagnosis [14], we recommend suspected colorectal cancer (CRC) and suspected SB cancer as indications for semi-urgent colon CE (CCE) and SBCE during the pandemic, respectively. We believe the complement of CE for gastrointestinal cancer investigation in the semi-urgent manner would catch up with the previous underdiagnosed cases, as reduction in endoscopy volume due to the pandemic has resulted in delayed gastrointestinal malignancy diagnosis [15]. Recommended indications for elective CE include upper gastrointestinal cancer screening (MCE or noncontact MCE [8]), CRC screening (CCE), Crohn's disease, celiac disease, iron-deficiency anemia, and polyposis syndrome (SBCE) [6].

Because CE currently cannot provide biopsy and therapeutic function, patients with the above-mentioned needs should be subsequently referred for EGD/enteroscopy/colonoscopy.

- Table 1 Recommended indications for urgent, semi-urgent and elective capsule endoscopy examination during the COVID-19 pandemic.

\begin{tabular}{|l|l|l|}
\hline Urgent CE & Semi-urgent CE & Elective CE \\
\hline $\begin{array}{l}\text { Suspected acute SB bleeding (eg, nonhematemesis gastrointes- } \\
\text { tinal bleeding after negative EGD and colonoscopy) (SBCE) }\end{array}$ & $\begin{array}{l}\text { Suspected upper gastrointestinal } \\
\text { cancer (MCE, noncontact MCE) }\end{array}$ & $\begin{array}{l}\text { Upper gastrointestinal cancer } \\
\text { screening (MCE, noncontact MCE) }\end{array}$ \\
\hline $\begin{array}{l}\text { Stable acute upper gastrointestinal bleeding (CE', MCE, noncon- } \\
\text { tact MCE) }\end{array}$ & Suspected CRC (CCE) & CRC screening (CCE) \\
\hline & Suspected SB cancer (SBCE) & Crohn's disease (SBCE) \\
\hline & & Celiac disease (SBCE) \\
\hline & & Iron-deficiency anemia (SBCE) \\
\hline $\begin{array}{l}\text { CCE, colon capsule endoscopy; CE, capsule endoscopy; CRC, colorectal cancer; ECD, esophagogastroduodenoscopy; MCE, magnetically controlled capsule endos- } \\
\text { Copy; SBCE, small bowel capsule endoscopy. } \\
1 \text { CE here denotes esophageal/upper gastrointestinal/small bowel CE. }\end{array}$ & Polyposis syndrome (SBCE) \\
\hline
\end{tabular}




\section{Requirements for patients}

Patients and their companions must wear medical masks during their hospital visit.

At the reception desk of the CE unit, patients and their companions should be first evaluated by temperature, COVID-19related symptoms (cough, fatigue, et al) and epidemiological history (a web-based platform is recommended for prescreening). SARS-CoV-2 nucleic acid test (chest computed tomography and routine blood testibng suggested as an alternative in case of limited nucleic acid test resources) within the previous 3 days (preferably on the same day) of the CE examination are also required for patients to determine suspected/confirmed COVID-19 or not. Those with fever or suspected/confirmed COVID-19 should be referred to fever clinics or isolation wards immediately [16].

Patients and their companions must use alcohol-based hand rubs to disinfect hands before entering the waiting area. The number of patients and their companions in the waiting area shall be limited to a minimum, and the distance between each other must exceed 1 meter [17].

Only the patient is allowed to enter the examination room and complete the CE under the instructions of the medical staff. A medical mask must be worn during the whole examination process.

\section{Requirements for medical staff}

Medical staff in the CE unit shall have normal temperature, no COVID-19-related symptoms and no epidemiological history. Otherwise, they should leave their post immediately and receive further medical intervention.

A medical mask must be worn on entering the hospital and the CE unit.

Medical staff at the reception desk of the CE unit shall follow general protection standards, including wearing a work uniform (or enhanced with isolation gown/single-use surgical gown), surgical mask, hair covering, and medical gloves.

Medical staff in the CE examination room must wear work uniforms (or enhanced with isolation gown/single-use surgical gown), surgical mask (or N95 mask), goggles, hair covering, latex gloves (replaced after each patient) and single-use shoe covers $[18,19]$. The number of medical staff in the CE examination room should be kept to a minimum (one medical staff member, in principle).

A medical mask must be replaced when it becomes damp, contaminated, or has been worn for over 4 hours. Hand washing should be done following the six-step hand rub technique for 2 minutes, or hands sanitized with alcohol-based hand rubs [20]. Hand washing should not be replaced by wearing gloves.

CE examination and reading/reporting should be separated. Sending electronic reports to the patients instead of paper reports is recommended.

\section{Disinfection of the capsule endoscopy} examination room

During CE examination, it is recommended to disinfect the air in the examination room continuously with dynamic medical air sterilizers.

For each paper, after examination, terminal disinfection is required $[18,19]$. The surface of equipment shall be disinfected by wiping with $75 \%$ alcohol. The ground shall be disinfected with chlorine disinfectants for 30 minutes. Disinfection with ultraviolet light or dynamic medical air sterilizers also must be conducted. After disinfection, windows should be opened for ventilation. Then the room can be put into use again for the next patient.

Portable data recorders returned the next day by the patients should be disinfected by wiping with $75 \%$ alcohol. A vest-type data recorder should be disinfected with ultraviolet light, $75 \%$ alcohol or ethylene oxide.

The use of central air conditioning should be avoided, except in special circumstances, in which case, timely replacement of vent filters is required.

\section{Emergency plan}

Patients and their companions should be followed up for up to 2 weeks after CE. If any of them has been confirmed to have COVID-19, his or her close contacts must be immediately traced and placed under medical observation.

\section{Competing interests}

The authors declare that they have no conflict of interest.

\section{References}

[1] Bedford ], Enria D, Giesecke J et al. COVID-19: towards controlling of a pandemic. Lancet 2020; 395: 1015-1018

[2] Chai N, Mei Z, Zhang W et al. Endoscopy works during the pandemic of coronavirus COVID-19: recommendations by the Chinese Society of Digestive Endoscopy. United European Gastroenterol J 2020; 8: 798-803

[3] Chiu PWY, Ng SC, Inoue $\mathrm{H}$ et al. Practice of endoscopy during COVID19 pandemic: position statements of the Asian Pacific Society for Digestive Endoscopy (APSDE-COVID statements). Gut 2020; 69: 991996

[4] Gralnek IM, Hassan C, Beilenhoff U et al. ESGE and ESGENA Position Statement on gastrointestinal endoscopy and the COVID-19 pandemic. Endoscopy 2020; 52: 483-490

[5] Zhang Y, Zhang X, Liu L et al. Suggestions for infection prevention and control in digestive endoscopy during current 2019-nCoV pneumonia outbreak in Wuhan, Hubei province, China. Endoscopy 2020; 52: 312-314

[6] Enns RA, Hookey L, Armstrong D et al. Clinical Practice Guidelines for the Use of Video Capsule Endoscopy. Gastroenterology 2017; 152: 497-514

[7] Digestive Endoscopy Committee of Chinese Endoscopist Association, Digestive Endoscopy Health Management and Checkup Committee of 
Chinese Endoscopist Association, Capsule Endoscopy Group of the Chinese Society of Digestive Endoscopy, et al. [The China expert consensus of clinical practice for magnetically controlled capsule gastroscopy (2017, Shanghai)]. Zhonghua Nei Ke Za Zhi 2017; 56: 876-884

[8] Pan J, Li Z, Liao Z. Noncontact endoscopy for infection-free gastric examination during the COVID-19 pandemic. VideoGIE 2020; 5: 402403

[9] Sung J], Tang RS, Ching JY et al. Use of capsule endoscopy in the emergency department as a triage of patients with GI bleeding. Gastrointest Endosc 2016; 84: 907-913

[10] Marya NB, Jawaid S, Foley A et al. A randomized controlled trial comparing efficacy of early video capsule endoscopy with standard of care in the approach to nonhematemesis GI bleeding (with videos). Gastrointest Endosc 2019; 89: 33-43

[11] Ching HL, Hale MF, Sidhu R et al. Magnetically assisted capsule endoscopy in suspected acute upper $\mathrm{Gl}$ bleeding versus esophagogastroduodenoscopy in detecting focal lesions. Gastrointest Endosc 2019; 90: 430-439

[12] Liao Z, Hou X, Lin-Hu EQ et al. Accuracy of magnetically controlled capsule endoscopy, compared with conventional gastroscopy in detection of gastric diseases. Clin Gastroenterol Hepatol 2016; 14: 1266-1273

[13] Zhao A], Qian YY, Sun H et al. Screening for gastric cancer with magnetically controlled capsule gastroscopy in asymptomatic individuals. Gastrointest Endosc 2018; 88: 466-474
[14] MacLeod C, Wilson P, Watson AJM. Colon capsule endoscopy: an innovative method for detecting colorectal pathology during the COVID-19 pandemic? Colorectal Dis 2020; 22: 621-624

[15] Lui TK, Leung K, Guo CG et al. Impacts of COVID-19 Pandemic on Gastrointestinal Endoscopy Volume and Diagnosis of Gastric and Colorectal Cancers: A Population-based Study. Gastroenterology 2020; 159: 1164-1166

[16] Qu JM, Wang C, Cao B et al. Guidance for the management of adult patients with coronavirus disease 2019. Chin Med J 2020; 133: 1575 1594

[17] Chu DK, Akl EA, Duda S et al. Physical distancing, face masks, and eye protection to prevent person-to-person transmission of SARS-CoV-2 and COVID-19: a systematic review and meta-analysis. Lancet 2020; 395: 1973-1987

[18] Calderwood AH, Day LW. ASGE Quality Assurance in Endoscopy Committee. et al. ASGE guideline for infection control during GI endoscopy. Gastrointest Endosc 2018; 87: 1167-1179

[19] Beilenhoff U, Biering H, Blum R et al. Reprocessing of flexible endoscopes and endoscopic accessories used in gastrointestinal endoscopy: Position Statement of the European Society of Gastrointestinal Endoscopy (ESGE) and European Society of Gastroenterology Nurses and Associates (ESGENA) - Update 2018. Endoscopy 2018; 50: 12051234

[20] Siddharta A, Pfaender S, Vielle NJ et al. Virucidal activity of World Health Organization-recommended formulations against enveloped viruses, Including Zika, Ebola, and emerging coronaviruses. J Infect Dis 2017; 215: 902-906 